\title{
SERT and BDNF polymorphisms interplay on neuroticism in borderline personality disorder
}

\author{
Valeria Salinas ${ }^{1,2}$, Juana Villarroe ${ }^{3,4}$, Hernán Silva ${ }^{3,4}$, Luisa Herrera5 ${ }^{5}$, Sonia Jerez ${ }^{3,4}$, Alejandra Zazueta6, \\ Cristián Montes ${ }^{3,4}$, Rodrigo Nieto $3,4,7$ and M. Leonor Bustamante ${ }^{4,5^{*}}$ (I)
}

\begin{abstract}
Objective: Genetic factors underlying different personality traits are not entirely understood, particularly how genes interact to modulate their effect. We studied 76 patients diagnosed with borderline personality disorder (BPD), characterized by extreme levels of personality traits, especially neuroticism (N), in which we genotyped two polymorphisms, the 5HTTLPR of the Serotonin transporter (SERT) gene, and the Val66Met of the Brain-derived neurotrophic factor (BDNF) gene.

Results: We found an association with SERT, where S-allele carriers had significantly higher levels of $\mathrm{N}$ than L-homozygous. Furthermore, we found that the protective effect of L-homozygosity is only evident on A-allele carriers of the BDNFVal66Met polymorphism. Genetic constitution in SERT and BDNF seems to be important in neuroticism, the most relevant personality trait on BPD.
\end{abstract}

Keywords: Genetics, Personality, Five-factor model, Gene interaction, 5HTTLPR

\section{Introduction}

Inter-individual differences in personality can be at least partially accounted for by genetic factors. Personality traits are predictors of the development and course of mental disorders, and it is not clear whether this association is explained by shared genetic influences or by a different mechanism. It is estimated that the genetic underpinnings of personality traits are extremely complex. Nevertheless, understanding them is relevant to unravel the biological bases of vulnerability to personality disorders as well as other mental illnesses.

Borderline personality disorder (BPD) is characterized by affective dysregulation and impulsivity that lead

\footnotetext{
*Correspondence: mbustamante@med.uchile.cl

${ }^{4}$ Department of Psychiatry and Mental Health, North Division, Faculty of Medicine, Universidad de Chile, Av. La Paz 1003, Recoleta, Santiago, Chile

Full list of author information is available at the end of the article
}

to impairments in interpersonal, cognitive, behavioral and emotional functioning. It affects approximately $20 \%$ of consultants to psychiatric services, and its severity is determined mainly by impulsive behavior, including self-injury [1]. Several studies agree that the best framework to study BPD is the five-factor model of personality (FFM) [2], that describes personality in terms of Neuroticism $(\mathrm{N})$, Extraversion $(\mathrm{E})$, Openness to experience $(\mathrm{O})$, Conscientiousness $(\mathrm{C})$ and Agreeableness $(\mathrm{A})$ [3]. In general, BPD can be understood as extreme levels of the FFM traits, specifically high levels of $\mathrm{N}$, and low levels of $\mathrm{A}, \mathrm{C}$, and $\mathrm{E}$ [4]. The levels of personality traits, especially $\mathrm{N}$, correlate with severity of impairment [5].

There is a moderate genetic contribution to normative personality traits. $\mathrm{N}$ is the personality trait that has the highest heritability [6]. On the other hand, the heritability of BPD has been estimated to be 40\% [7]. Furthermore, there is a high degree of correlation between BPD and N, which is probably due to a shared genetic contribution

(c) The Author(s) 2020. This article is licensed under a Creative Commons Attribution 4.0 International License, which permits use, sharing, adaptation, distribution and reproduction in any medium or format, as long as you give appropriate credit to the original author(s) and the source, provide a link to the Creative Commons licence, and indicate if changes were made. The images or other third party material in this article are included in the article's Creative Commons licence, unless indicated otherwise in a credit line to the material. If material is not included in the article's Creative Commons licence and your intended use is not permitted by statutory regulation or exceeds the permitted use, you will need to obtain permission directly from the copyright holder. To view a copy of this licence, visit http://creativeco mmons.org/licenses/by/4.0/. The Creative Commons Public Domain Dedication waiver (http://creativecommons.org/publicdomain/ zero/1.0/) applies to the data made available in this article, unless otherwise stated in a credit line to the data. 
[8]. Sharing of genetic risk factors has also been demonstrated for $\mathrm{N}$ and $\mathrm{O}$ and several psychiatric disorders including schizophrenia and mood disorders [9], which highlights the relevance of investigating genetic factors across conditions. For other personality traits, evidence suggests that the genetic contributions are smaller (with the exception of E), and that correlation with mental disorders is not explained by shared genetic factors.

In order to identify genetic factors explaining interindividual differences in personality, we studied the association between a polymorphism in the serotonin transporter (SERT) gene known as 5HTTLPR (Serotonin transporter-linked promoter region) and one in the brain-derived neurotrophic factor $(B D N F)$ gene (G196A, or Val66Met, rs6265), with FFM personality traits, in a sample of 76 individuals with borderline personality disorder (BPD). We focused on a defined group because we expect their characteristic personality profile would decrease the complexity of the phenotype and thus increase the power of our study. Furthermore, clinical variability among patients with BPD determines longterm outcome and therefore understanding its biological basis is also a relevant matter.

\section{Main text \\ Methods and materials \\ Individuals and clinical measures}

The study population sample was comprised of 76 patients diagnosed with BPD. All the cases were recruited at the University Psychiatric Clinic of Universidad de Chile. Structured interviews, SCID-I [10] and SCID-II [11], were used to identify DSM-IV disorders on Axis I and II. Exclusion criteria were history of mania or psychosis, present substance abuse, present depressive episode, and severe medical illness that could interfere with the clinical severity. All patients are of Chilean descent, and they all belonged to the same socioeconomic stratum (Stratum II) as defined by income and occupation [12].

A sample of 80 individuals with no mental disorders was recruited for comparing genotypic frequencies. They were screened using the MINI International Psychiatric Interview [13]. Any present or past mental disorder was an exclusion criterion, as well as any relevant medical disease as established by anamnesis. All controls are of Chilean descent, and they belonged to either II or III socioeconomic strata, meaning that they had either medium or low income and occupation levels.

Personality traits were studied according to the FFM, using the Spanish version of the NEO-FF Inventory [14]. The questionnaires were self-administered under the supervision of a research assistant (either a clinical psychologist or a psychiatry resident).

\section{Laboratory procedures}

DNA was extracted from peripheral blood leukocytes using commercially available kits and stored at $-80{ }^{\circ} \mathrm{C}$ until required. DNA integrity was evaluated using agarose gel electrophoresis, and quantification was carried out by microvolume spectrophotometry using a Nanodrop(R) equipment.

Genotyping of the rs6265 single nucleotide polymorphism (SNP) was carried out by RT-PCR, specifically using the TaqMan ${ }^{\circledR}$ SNP Assays allele discrimination technique from Applied Biosystems. The components of the RT-PCR are in concentration and volume $\mathrm{H}_{2} \mathrm{O} 5.5 \mu \mathrm{l}$, Mastermix $(2 \times) 2 \mu$ l, TaqMan Assay $(20 \times) 0.50 \mu$ l, DNA $(5 \mathrm{ng} / \mathrm{Ul}) 2 \mu \mathrm{l}$. Genotypes were obtained from the interpretation of the graphics using the StepOne software which is incorporated in the equipment.

5HTTLPR polymorphism genotyping was performed using the conventional PCR method. We used the primers 5'TCCTCCGCTTTGGCGCCTCTTCC ${ }^{\prime}$ ' and 5'TGG GGGTTGCAGGGGAGATCCCG3' [15]. The reaction was performed in total volume of $17 \mu$ l containing Taq polymerase and buffer; the equipment used is Thermal Cycler Operations, model PTC-100. PCR products were visualized by electrophoresis in $2 \% \mathrm{w} / \mathrm{v}$ agarose gels. PCR amplification allowed obtaining fragments or bands of 512 for L-allele and $469 \mathrm{bp}$ for S-allele.

\section{Statistical analysis}

Univariate statistical analysis was performed using SPSS 13.0. Descriptive statistics included estimation of means and standard deviation (SD). Shapiro-Wilk test was used to establish normality of the data. Comparisons between groups defined by their genotype comparisons were made through ANOVA. Hardy-Weinberg equilibrium was studied by Goodness of Fit Chi square test. A $p$-value $<0.05$ was considered statistically significant.

\section{Results}

The patients' sample was composed of $73.1 \%$ women, with a mean age of 34.2 , with no differences in age distribution between females and males. The control sample was composed of $66.3 \%$ women, with a mean age of 33.7 years old.

Allelic frequencies for both polymorphisms showed no differences between patients and controls. For BDNF Val66Met polymorphism, the frequencies in patients were $\mathrm{G}=0.79, \mathrm{~A}=0.21$; in controls, $\mathrm{G}=0.76, \mathrm{~A}=0.24$. For 5HTTLPR, the frequencies in patients were $\mathrm{L}=0.48$, $\mathrm{S}=0.52$; and in controls $\mathrm{L}=0.49, \mathrm{~S}=0.51$.

Mean scores $( \pm \mathrm{SD})$ for personality traits for the whole group of patients were: N: $69.84( \pm 14.73)$; $\mathrm{E}: 43.61$ ( \pm 15.79$)$; O: 51.14 ( \pm 14.85$)$; C: 40.68 ( \pm 11.33$) ;$ A: 39.63 
$( \pm 12.07)$. For comparison purposes, mean values for the general population are 46-55 for each trait. Scores 56-65 are considered high, and $>65$ very high, while scores $36-45$ are considered low, and $<36$, very low [16].

The scores for personality traits in the sample divided by the genotypes of the participants are presented in Table 1. For rs6265, the allelic and genotypic frequencies of the sample were in $\mathrm{H}-\mathrm{W}$ equilibrium $(p=0.064)$. For 5HTTLPR genotypes, the allelic and genotypic frequencies of the sample deviated from $\mathrm{H}$ to $\mathrm{W}$ equilibrium $(p=0.055)$.

There were no significant differences observed among $B D N F$ genotypes in any of the personality traits, although a trend was observed in $\mathrm{N}$ score $(p=0.055)$.

Significant differences $(p=0.022)$ were observed among SERT genotypes in the N score, but not among the other personality traits. The $\mathrm{N}$ score of S-allele carriers was on the "very high" range (score higher than 65), whereas L-allele homozygous had N scores on the "high" range (score between 56 and 65).

Figure 1 displays the interaction between the two genes, showing that L-allele homozygosity correlates with lower levels of $\mathrm{N}$, only on A-allele carriers. $\mathrm{S}$-carriers had higher levels of $\mathrm{N}$, regardless of their $B D N F$ genotype. In fact, $\mathrm{S}$-carriers/GG individuals had $73.6 \pm 13.8$ (mean $\pm \mathrm{SD}$ ), while S-carriers/A carriers had $71.34 \pm 11.79$; on the other hand, G-allele homozygous had "very high" N scores regardless of their SERT genotype. GG/LL individuals had $70.1 \pm 17.06$, similar to GG/S-carriers (see above). These differences are not statistically significant, but this trend is interesting because the differences between subgroups are of potential clinical impact. In fact, the subgroup of LL/A-carriers has mean scores of $\mathrm{N}$ in the normal range $(52.29 \pm 11.84)$.

No interactions were observed with the other personality traits (data not shown).

\section{Discussion}

In our sample of 76 patients with BPD, we observed higher levels of $\mathrm{N}$ in carriers of the S-allele of the SERT

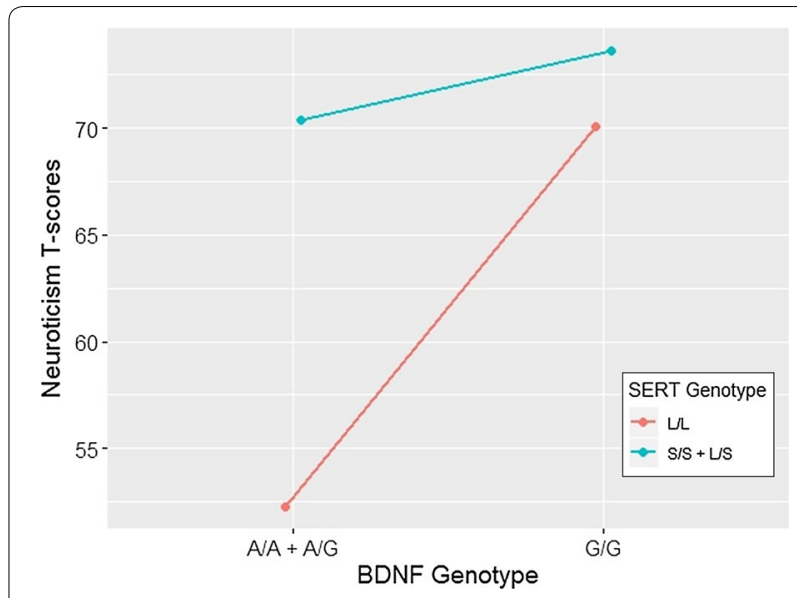

Fig. 1 Neuroticism score of rs6265 A-allele carriers vs non-carriers, according to their SERT genotype

5HTTLPR polymorphism. Furthermore, we observed a trend for an interaction between this polymorphism and rs6265 of $B D N F$ gene, where the presence of the A allele of rs6265 have a trend to associates to lower levels of $\mathrm{N}$ only in L-allele homozygous.

Studying intra-class variability in psychiatric disorders is a useful strategy for understanding particularly complex phenotypes like personality traits. Of the five personality traits of the FFM, the one that has shown a more significant genetic contribution, and a more consistent relationship with $\mathrm{BPD}$ is $\mathrm{N}$, and therefore our negative results with respect to other traits are not surprising. We have focused on $\mathrm{N}$ because of its impact on modulating the risk (of the general population) for suffering mental disorders and of BPD patients for having a worse outcome.

The S-allele of the 5HTTLPR has been widely considered as a risk factor for several psychiatric traits. However, studies of S-allele of the 5HTTLPR association with $\mathrm{N}$ have produced inconsistent results. One possible explanation for this is that its effect may be genderspecific [17]. Regarding BPD, several studies provide

Table 1 Personality traits scores by BDNF Val66Met and 5HTTLPR genotypes in two groups

\begin{tabular}{|c|c|c|c|c|c|c|}
\hline \multirow[t]{2}{*}{$N=76$} & \multicolumn{2}{|c|}{$\begin{array}{l}\text { Average score by BDNF Val66Met } \\
\text { genotypes }\end{array}$} & \multirow[t]{2}{*}{$p$ value } & \multicolumn{2}{|c|}{ Average score by 5HTTLPR genotypes } & \multirow[t]{2}{*}{$p$ value } \\
\hline & $\mathrm{G} / \mathrm{G}(\mathrm{N}=47)$ & $A / A+A / G(N=29)$ & & $\mathrm{L} / \mathrm{L}(\mathrm{N}=18)$ & $\mathrm{S} / \mathrm{S}+\mathrm{L} / \mathrm{S}(\mathrm{N}=55)$ & \\
\hline Neuroticism (M $\pm \mathrm{SD})$ & $72.72 \pm 14.56$ & $66.16 \pm 14.32$ & 0.055 & $63.52 \pm 17.39$ & $72.35 \pm 13.22$ & 0.022 \\
\hline Extraversion $(\mathrm{M} \pm \mathrm{SD})$ & $43.6 \pm 16.39$ & $44.23 \pm 14.67$ & 0.864 & $45.21 \pm 18.78$ & $43.40 \pm 14.67$ & 0.665 \\
\hline Openness to experience $(M \pm S D)$ & $53.25 \pm 14.49$ & $47.72 \pm 15.04$ & 0.155 & $50.22 \pm 16.67$ & $51.43 \pm 14.38$ & 0.765 \\
\hline Conscientiousness (M $\pm \mathrm{SD})$ & $40.17 \pm 11.77$ & $41.51 \pm 10.72$ & 0.618 & $38.66 \pm 11.15$ & $41.31 \pm 11.40$ & 0.391 \\
\hline Agreeableness $(\mathrm{M} \pm \mathrm{SD})$ & $39.93 \pm 12.11$ & $39.13 \pm 12.21$ & 0.782 & $39.72 \pm 11.04$ & $39.60 \pm 12.47$ & 0.971 \\
\hline
\end{tabular}


evidence of a modulating effect on the clinical features, where the S-allele determines worse outcome (for a systematic review see [18]).

As for BDNF rs6265, a meta-analysis [19] showed that A-allele carriers had significantly lower $\mathrm{N}$ scores than G-allele homozygous, in line with other studies suggesting that A-allele exerts a protective effect for psychiatric disorders [20]. However, this is not without controversy, because there is also evidence of association of the A-allele to impairment of neural structure and function, and higher levels of anxiety [21]. rs6265 has also been implicated in modulating the clinical features of BPD, including impulsive aggression [22], and susceptibility to environmental stress [23].

These candidate polymorphisms on SERT and BDNF genes have shown to modulate negative emotion processing $[24,25]$. There are also biological and functional relationships between BDNF and serotonin, as BDNF promotes development of serotonergic synapses. Therefore, it is plausible that the effect of variants on these two genes interact to modulate personality traits, especially $\mathrm{N}$ which is closely related to anxiety. In fact, a study conducted on a large community-based sample found an interaction between rs6265 and 5HTTLPR where L-allele homozygous scored lower on $\mathrm{N}$ neuroticism only in the absence of the A-allele [21]. Interaction between rs6265 and 5HTTLPR has been observed in other traits related to anxious behavior, including conscientiousness (from the FFM), worry, cognitive reactivity and negative affect $[26,27]$.

The present study is unique in that we studied the effects of these two polymorphisms within the class of BPD and found an effect on the levels of N. Our results help to understand the differences between BPD patients that can have an impact on clinical outcome. Also, because there are shared genetic contributions to $\mathrm{N}$ and to $\mathrm{BPD}$, this design can help understand $\mathrm{N}$ as a general trait.

\section{Limitations}

We must acknowledge relevant limitations in our study. Our sample size is small, which leads to a loss of statistical power. However, we expect that our study is sufficiently robust because of the use of stringent exclusion criteria and a thorough clinical characterization. Interestingly, a recent study using factor analysis revealed two subclusters of $\mathrm{N}$ that have been named "Worry" and "Depressive Affect" and whose genetic influences can be separate [28]. To date, these two clusters have not been studied among BPD patients, or whether our candidate polymorphisms act differentially on these two features. This is certainly an aspect worth exploring in future studies.
Another limitation to acknowledge is that other variants of the promoter region of SERT gene were not studied. A SNP (rs25531, A/G) harbored in the variable region of the 5HTTLPR has been described that determines three main alleles: the S-allele, an L-A-allele, and an L-G-allele. The L-G has the same transcriptional efficiency as the $\mathrm{S}$-allele, and therefore its presence may generate confounding results. While we did not include this analysis, we do not expect this to have an influence on our results, because the L-G allele has a very low frequency in Hispanic populations, and in fact a study found no L-G homozygous individuals [29].

Further studies must be performed including these and other genes in larger samples for a better understanding of the interplay of SERT and BDNF in Neuroticism, the most relevant personality trait in BPD.

\section{Abbreviations}

5HTTLPR: Serotonin transporter-linked polymorphic region; A: Agreeableness: BPD: Borderline personality disorder; BDNF: Brain-derived neurotrophic factor; C: Conscientiousness; E: Extraversion; FFM: Five-factor model of personality; N: Neuroticism; SERT: Serotonin transporter; SNP: Single nucleotide polymorphism.

\section{Acknowledgements}

The authors thank all of the patients that participated in the study. We also thank the members of the Personality Disorders Unit of University Psychiatric Clinic who participated in patient evaluations.

\section{Authors' contributions}

All authors participated in the research, and read and approved the final version of the manuscript. Individual contributions are detailed below: VS performed the analysis, wrote the manuscript. JV conceived the analysis, collected data, provided critical input for the manuscript. HS conceived the analysis, provided critical input for the manuscript. LH designed the analysis, provided critical input for the manuscript. AZ performed the analysis, provided critical input for the manuscript. SJ conceived the analysis, provided critical input for the manuscript. CM collected the data, provided critical input for the manuscript. RN provided critical input for the manuscript. MB conceived and designed the analysis, led the writing of the manuscript with input from all authors. All authors read and approved the final manuscript.

\section{Funding}

This work was funded by Consejo Nacional de Ciencia y Tecnología (CONICYT), Chile, Grant Fondecyt 1071045, and Ministerio de Economia, Chile Grant ICM-P09 (Biomedical Neuroscience Institute). Funding agencies participated neither on designing the study, nor on collecting, analyzing or interpreting data, nor on writing the manuscript.

\section{Availability of data and materials}

The data will not be shared in a public repository because during recruitment of subjects this authorization was not requested in the informed consent process. Individual requests for data access will be reviewed by the corresponding author.

\section{Ethics approval and consent to participate}

The protocol was approved by the Institutional Review Board of the Faculty of Medicine of Universidad de Chile, and all the individuals signed written informed consent.

Consent for publication

Not applicable. 


\section{Competing interests}

The authors declare that they have no competing interests.

\section{Author details}

${ }^{1}$ Neurogenetics Clinic and Laboratory, University Neurology Center and Neurology Section, J.M. Ramos Mejía, Hospital, Faculty of Medicine, Universidad de Buenos Aires, Buenos Aires, Argentina. ${ }^{2}$ Precision Medicine and Clinical Genomics Program, Translational Medicine Research Institute, Faculty of Biomedical Sciences, Universidad Austral-CONICET, Buenos Aires, Argentina. ${ }^{3}$ University Psychiatric Clinic, Clinical Hospital, Universidad de Chile, Santiago, Chile. ${ }^{4}$ Department of Psychiatry and Mental Health, North Division, Faculty of Medicine, Universidad de Chile, Av. La Paz 1003, Recoleta, Santiago, Chile. ${ }^{5}$ Human Genetics Program, Biomedical Sciences Institute, Faculty of Medicine, Universidad de Chile, Santiago, Chile. ${ }^{6}$ Program in Sciences and Engineering for Health, Universidad de Valparaíso, Valparaíso, Chile. ${ }^{7}$ Department of Neuroscience, Faculty of Medicine, Universidad de Chile, Santiago, Chile.

Received: 21 November 2019 Accepted: 28 January 2020 Published online: 07 February 2020

\section{References}

1. Lieb K, Zanarini M, Schmahl C, Linehan M, Bohus M. Borderline personality disorder. Lancet. 2004;364:453-61.

2. Clark LA. Assessment and diagnosis of personality disorder: perennial issues and an emerging reconceptualization. Annu Rev Psychol. 2007;58:227-57

3. Mullins-Sweatt SN, Edmundson M, Sauer-Zavala S, Lynam DR, Miller JD, Widiger TA. Five-factor measure of borderline personality traits. J Pers Assess. 2012;94(5):475-87.

4. Samuel DB, Widiger TA. A meta-analytic review of the relationships between the five-factor model and DSM-IV-TR personality disorders: a facet level analysis. Clin Psychol Rev. 2008;28(8):1326-42.

5. Ralevski E, et al. Avoidant personality disorder and social phobia: distinct enough to be separate disorders? Acta Psychiatr Scand. 2005;112(3):208-14.

6. Czajkowski N, et al. A twin study of normative personality and DSM-IV personality disorder criterion counts: evidence for separate genetic influences. Am J Psychiatry. 2018;175(7):649-56.

7. Amad A, Ramoz N, Thomas P, Jardri R, Gorwood P. Genetics of borderline personality disorder: systematic review and proposal of an integrative model. Neurosci Biobehav Rev. 2014;40:6-19.

8. Distel MA, et al. Familial resemblance of borderline personality disorder features: genetic or cultural transmission. PLoS ONE. 2009;4(4):e5334.

9. Lo MT, et al. Genome-wide analyses for personality traits identify six genomic loci and show correlations with psychiatric disorders. Nat Genet. 2017:49(1):152.

10. First MB, Spitzer RL, Gibbon M, Williams J. Structured clinical interview for DSM-IV-TR Axis I disorders, research version. New York: Biometrics Research, New York State Psychiatric Institute; 2002.

11. First M, Gibbon M, Spitzer R. Structured clinical interview for DSM-IV axis II personality disorders (SCID-II). Washington: Am Psychiatr Press Inc.; 1997.

12. Valenzuela CY. Human sociogenetics. Biol Res. 2011;44(4):393-404.

13. Lecrubier $Y$, et al. The mini international neuropsychiatric interview (MINI). A short diagnostic structured interview: reliability and validity according to the CIDI. Eur Psychiatry. 1997;12(5):224-31.
14. Manga D, Ramos F, Morán C. The Spanish norms of the NEO five-factor inventory: new data and analyses for its improvement. Int J Psychol Psychol Ther. 2004;4:639-48.

15. Wendland JR, Martin BJ, Kruse MR, Lesch K-P, Murphy DL. Simultaneous genotyping of four functional loci of human SLC6A4, with a reappraisal of 5-HTTLPR and rs25531. Mol Psychiatry. 2006;11(3):224-6.

16. Costa P, McCrae R. Revised NEO personality inventory (NEO-PI-R) and NEO five factor model (NEO-FFI) professional manual Spanish version. 2nd ed. Madrid:TEA Ediciones SA; 2002

17. Gressier F, Calati R, Serretti A. 5-HTTLPR and gender differences in affective disorders: a systematic review. J Affect Disord. 2016;190:193-207.

18. Calati R, Gressier F, Balestri M, Serretti A. Genetic modulation of borderline personality disorder: systematic review and meta-analysis. J Psychiatr Res. 2013:47:1275-87.

19. Frustaci A, Pozzi G, Gianfagna F, Manzoli L, Boccia S. Meta-analysis of the brain-derived neurotrophic factor gene (BDNF) Val66Met polymorphism in anxiety disorders and anxiety-related personality traits. Neuropsychobiology. 2008:58:163-70.

20. Lehto K, Mäestu J, Kiive E, Veidebaum T, Harro J. BDNF Val66Met genotype and neuroticism predict life stress: a longitudinal study from childhood to adulthood. Eur Neuropsychopharmacol. 2016;26(3):562-9.

21. Terracciano A, et al. BDNF Val66Met is associated with introversion and interacts with 5-HTTLPR to influence neuroticism. Neuropsychopharmacology. 2010;35(5):1083-9.

22. Wagner S, Baskaya Ö, Dahmen N, Lieb K, Tadić A. Modulatory role of the brain-derived neurotrophic factor Val66Met polymorphism on the effects of serious life events on impulsive aggression in borderline personality disorder. Genes Brain Behav. 2010;9(1):97-102.

23. Bresin K, Finy MS, Verona E. Childhood emotional environment and self-injurious behaviors: the moderating role of the BDNF Val66Met polymorphism. J Affect Disord. 2013;150(2):594-600.

24. Kourmouli N, Samakouri M, Mamatsiou A, Trypsianis G, Livaditis M, Veletza S. Effect of BDNF Val66Met and serotonin transporter 5-HTTLPR polymorphisms on psychopathological characteristics in a sample of university students. Psychiatr Genet. 2013;23(5):188-97.

25. Perez-Rodriguez MM, et al. Brain-derived neurotrophic factor Val66Met genotype modulates amygdala habituation. Psychiatry Res Neuroimaging. 2017;263:85-92.

26. Conway CC, Slavich GM, Hammen C. Dysfunctional attitudes and affective responses to daily stressors: separating cognitive, genetic, and clinical influences on stress reactivity. Cognit Ther Res. 2015;39(3):366-77.

27. Khandaker GM, Pearson RM, Zammit S, Lewis G, Jones PB. Association of serum interleukin 6 and $C$-reactive protein in childhood with depression and psychosis in young adult life. JAMA Psychiatry. 2014;71(10):1121-8.

28. Nangel NM, et al. Meta-analysis of genome-wide association studies for neuroticism in 449,484 individuals identifies novel genetic loci and pathways. Nat Genet. 2018;50(7):920-7.

29. Haberstick BC, et al. Population frequencies of the triallelic 5HTTLPR in six ethnicially diverse samples from North America, Southeast Asia, and Africa. Calcif Tissue Int. 2015;45:255-61.

\section{Publisher's Note}

Springer Nature remains neutral with regard to jurisdictional claims in published maps and institutional affiliations. 